\title{
Jadwal Kegiatan pada Sekolah Sehari Penuh dalam Menanamkan Kedisiplinan
}

\author{
Zyaqiah Almuna Wara \\ Serli Marlina \\ Pendidikan Guru Pendidikan Anak Usia Dini Fakultas Ilmu Pendidikan \\ Universitas Negeri Padang \\ Email: zyaqiahalmunawara01@gmail.com
}

Received March 2019, Accepted April 2019, Published April 2019

\begin{abstract}
This study aims to describe about the application activity schedule of full day school in Primagama Creative Kindegarten Padang. This study used a descriptive method with a qualitative approach. Informants from this study were principal and full day teachers. The techniques of data collection in this study were observation technique, interview technique, and documentation technique. The data analysis techniqueused was data triangulation technique. The results of the study were generally known that the application of activity schedule of dull day school in instilling disciplinary in Primagama Creative Kindegarten Padang have been well implemented. The teachers have made planning, implementation, and evaluation that was able to develop children's discipline attitudes through habituation with scheduled activities. So, it can be concluded that planning, implementation, and evaluation carried out in order to instill a discipline in children was accordance with the guidelines designed by the teachers.
\end{abstract}

Keywords: Activity Schedule, Full Day School, Disciplinary

Abstrak: Penelitian ini bertujuan untuk mendeskripsikan tentang penerapan activity schedule of full day school di Taman Kanak-kanak Kreatif Primagama Padang, Penelitian ini menggunakan metode deskriptif dengan pendekatan kualitatif. Informan dari penelitian ini adalah kepala sekolah dan guru full day. Teknik pengumpulan data dalam penelitian ini menggunakan teknik observasi, teknik wawancara, dan teknik dokumentasi. Teknik analisis data yang digunakan adalah teknik triangulasi data. Hasil penelitian secara umum diketahui bahwa penerapan activity schedule of full day school dalam menanamkan kedisiplinan di Taman Kanak-kanak Kreatif Primagama Padang sudah terlaksana dengan baik. Guru telah membuat perencanaan, pelaksanaan, dan evaluasi yang mampu mengembangkan sikap disiplin anak melalui pembiasaan dengan kegiatan terjadwal. Sehingga dapat disimpulkan bahwa dalam perencanaan, pelaksanaan, dan evaluasi yang dilakukan dalam menanamkan sikap disiplin pada anak telah sesuai dengan acuan yang dirancang oleh guru.

Kata Kunci: Jadwal Kegiatan, Sekolah Sehari Penuh, Disiplin

\section{PENDAHULUAN}

Berdasarkan pasal 28 Undang-undang Sistem Pendidikan Nasional Nomor 20/2003 ayat 1 , yang termasuk anak usia dini adalah anak yang berusia pada rentang 0-6 tahun. Anak usia dini memiliki karakteristik yang bersifat egosentris, unik, dan kaya imajinasi. Pada usia dini, tahap perkembangan dan pertumbuhan sangat menentukan masa depan anak. Masa ini disebut dengan golden age atau masa keemasan. Aspek perkembangan anak dapat berkembang dengan adanya pemberian stimulus baik dari keluarga yang terdekat maupun lingkungan sekitar anak. Untuk itu, salah satu cara untuk mengembangkan aspek perkembangan anak yaitu melalui pendidikan anak usia dini.

Pendidikan anak usia dini merupakan salah satu pendidikan di Indonesia yang merupakan investasi besar bagi bangsa. Pendidikan anak usia dini merupakan suatu upaya pembinaan yang ditujukan kepada anak sejak lahir sampai dengan usia enam tahun. Taman Kanak-kanak merupakan satuan PAUD pada jalur pendidikan formal. Taman Kanakkanak memberi kesempatan kepada anak untuk mengembangkan kepribadian dan potensi secara maksimal melalui kurikulum, rancangan pembelajaran harian, bulanan, maupun semester. 
Jurnal PG-PAUD Trunojoyo : Jurnal Pendidikan dan Pembelajaran Anak Usia Dini, Volume 6,

Pembelajaran di Taman Kanak-kanak tidak hanya setengah hari saja akan tetapi ada beberapa sekolah yang menerapkan sekolah sehari penuh atau yang dikenal dengan sebutan full day school. Menurut Siregar (2017:311) program ini bertujuan agar terwujudnya pendidikan secara utuh, terwujudnya intensifikasi dan efektivitas proses edukasi, dan efektif dalam mengaplikasikan kemampuan anak dalam segala hal. Adapun rancangan kegiatan pada full day school telah disusun terlebih dahulu dalam bentuk jadwal kegiatan atau activity schedule.

Activity schedule adalah aktivitasaktivitas yang telah disusun atau direncanakan sesuai jadwalnya dengan waktu pelaksanaan yang terperinci. Menurut McClannahan dan Krantz (dalam Budźinska, 2014:68) activity schedule adalah serangkaian gambar atau katakata yang mengisyaratkan seseorang untuk terlibat dalan kegiatan tertentu dan dalam melakukan tugas. Melalui activity schedule yang dibiasakan sejak dini pada anak dapat mempengaruhi faktor penentu bagi anak untuk memenuhi tugas dan kewajibannya dengan baik. Hal ini tentu saja juga mempengaruhi prestasi belajar anak. Banyaknya manfaat yang diperoleh anak dari penerapan activity schedule salah satunya ialah disiplin.

Disiplin merupakan salah satu kebutuhan dasar anak dalam rangka pembentukan dan pengembangan watak secara sehat. Tujuan dari disiplin ialah agar anak dapat secara kreatif dan dinamis dalam mengembangkan hidupnya di kemudian hari. Selain itu, disiplin juga bertujuan untuk mengarahkan anak agar belajar mengenai hal-hal baik yang merupakan persiapan bagi masa dewasa dan membentuk prilaku sedemikian rupa sesuai dengan peran-peran yang diterapkan.

Berdasarkan uraian di atas dan hasil observari awal yang peneliti lakukan di Taman Kanak-kanak Kreatif Primagama Padang. Peneliti menemukan bahwa Taman Kanak-kanak Kratif Primagama Padang memiliki program full day dengan activity schedule yang telah dirancang dan disusun sesuai dengan kebutuhan anak. Penerapan activity schedule yang dilakukan terhadap anak-anak full day selama ini dilakukan dengan pembiasaan yang diterapkan kepada anak yaitu dari hari senin hingga hari jumat pukul 08.00-16.30 WIB. Kesuksesan mendidik anak bisa terlihat dari terlaksananya pembelajaran atau kegiatan yang direncanakan oleh pihak sekolah sebab tujuan awal activity schedule ialah membuat anak terlatih dan bisa menata jadwalnya dengan disiplin.

\section{METODE}

Jenis penelitian ini menggunakan pendekatakan kualitatif dengan metode deskriptif. Subjek penelitian ini adalah sembilan anak full day yang berusia 4-6 tahun di Taman Kanak-kanak Kreatif Primagama Padang. Denzin dan Lincoln (dalam Moleong, 2009:5) mengemukakan bahwa penelitian kualitatif adalah penelitian yang menggunakan latar ilmiah, dengan maksud menafsirkan fenomena yang terjadi dan dilakukan dengan jalan melibatkan berbagai metode yang ada. Adapun metode yang digunakan yaitu metode deskriptif, sebagaimana Arikunto (2016:234) menyatakan bahwa pendekatan deskriptif ini merupakan penelitian yang dimaksudkan untuk mengumpulkan informasi mengenai status gejala yang ada menurut apa adanya pada saat penelitian dilakukan.

Instrumen penelitian yang digunakan dalam penelitian ini adalah format observasi, format wawancara, dan format dokumentasi sebagai bukti bahwa peneliti melakukan pengamatan terhadap apa yang ingin di teliti. Teknik pengumpulan data yang digunakan adalah teknik observasi, teknik wawancara, dan teknik dokumentasi. Untuk teknik analisis data yang digunakan adalah pengumpulan data, reduksi data, penyajian data, dan verifikasi data. Sebagaimana Miles dan Huberman (dalam Sugiyono, 2017:335) menyatakan bahwa aktivitas dalam analisis data kualitatif dilakukan secara interaktif dan berlangsung secara terus menerus hingga datanya jenuh.

Teknik pengabsahan data dalam penelitian ini menggunakan teknik triangulasi data. Peneliti meneliti kebenaran data dari beberapa sumber seperti kepala sekolah dan guru. kemudian peneliti melihat kebenaran data melalui teknik dan dokumentasi sehingga didapatkan kebenaran penelitian. Teknik pengabsahan data berhubungan dengan tingkat 
keberan dari data yang telah peneliti peroleh atau kumpulkan melalui penelitian kualitatif.

\section{HASIL DAN PEMBAHASAN}

\section{Hasil}

Taman Kanak-kanak Kreatif Primagama Padang yang beralamat di Jalan Palupuh Nomor 11 Jati Baru Kecamatan Padang Timur Kota Padang ini merupakan sekolah yang berakreditasi A. Jadwal harian di sekolah ini berlangsung dari hari SeninJumat yang mana dimulai dari pukul 08.00 WIB sampai pukul 16.30 WIB sebagaimana yang ditunjukkan pada tabel 1. Seperti pada umumnya, proses belajar mengajar mulai pada pukul 08.00-12.00 WIB. Kemudian dilanjutkan dengan program full day dari pukul 12.00-16.30 WIB.

Penerapan activity schedule of full day school ini guru melakukan perencanaan, pelaksanaan, dan evaluasi kegiatan. Setiap tahun ajaran baru, guru melakukan perencanan terhadap kegiatan yang akan anak lakukan, khususnya pada pukul 12.00-16.30 WIB. Sedangkan pukul 08.00-12.00 WIB sudah dirancang dalam RPPH yang diterapkan dalam proses belajar mengajar di kelas masing-masing. Artinya, layanan pembelajaran terpisah dari kegiatan pagi hari dan sore hari. Perencanaan ini disesuaikan dengan kebutuhan anak yang mana tujuannya agar anak disiplin dan mandiri dalam menjalani kehidupannya sehari-hari dengan baik dan teratur.

Pelaksanaan activity schedule of full day school ini dilakukan selama lima hari, yaitu senin-jumat. Setiap sekali sebulan, sekolah ini melakukan kegiatan berenang di Hotel Grand Sari Padang dan setiap sekali tiga bulan sekolah mengadakan field trip dan outbound, seperti ke Bandara International Minangkabau, Kebun Binatang, Pantai, dan tempat wisata setempat. Lifeskill yang dilakukan seperti menggelinding simpai, memasang dan melepas kancing baju, memasang dan melepas kaus kaki dan sepatu, menyisir rambut, merangkak dan merayap, dan sebagainya. Lifeskill berhubungan dengan kehidupan praktis anak.
Tabel 1. Activity Schedule of Full Day School di TK Kreatif Primagama Padang

\begin{tabular}{|c|c|c|}
\hline No & Waktu & Kegiatan \\
\hline 1 & $\begin{array}{l}08.00-08.15 \\
\text { WIB }\end{array}$ & Ikrar \\
\hline 2 & $\begin{array}{l}08.15-08.30 \\
\text { WIB }\end{array}$ & SOP opening \\
\hline 3 & $\begin{array}{l}08.30-09.30 \\
\text { WIB }\end{array}$ & Focus theme \\
\hline 4 & $\begin{array}{l}09.30-09.40 \\
\text { WIB }\end{array}$ & SOP lifeskill \\
\hline 5 & $\begin{array}{l}09.40-10.00 \\
\text { WIB }\end{array}$ & Review the lesson \\
\hline 6 & $\begin{array}{l}10.00-10.15 \\
\text { WIB }\end{array}$ & Take a break \\
\hline 7 & $\begin{array}{l}10.15-10.30 \\
\text { WIB }\end{array}$ & Snack time \\
\hline 8 & $\begin{array}{l}10.30-11.00 \\
\text { WIB }\end{array}$ & Closing \\
\hline 9 & $\begin{array}{l}11.00-12.00 \\
\text { WIB }\end{array}$ & Talents day \\
\hline 10 & $\begin{array}{l}12.00-12.15 \\
\text { WIB }\end{array}$ & Change clothes \\
\hline 11 & $\begin{array}{l}12.15-12.30 \\
\text { WIB }\end{array}$ & Lunch \\
\hline 12 & $\begin{array}{l}12.30-13.00 \\
\text { WIB }\end{array}$ & Pray Dzuhur \\
\hline 13 & $\begin{array}{l}13.00-13.15 \\
\text { WIB }\end{array}$ & Toileting \\
\hline 14 & $\begin{array}{l}13.15-15.00 \\
\text { WIB }\end{array}$ & Taking nap \\
\hline 15 & $\begin{array}{l}15.00-15.10 \\
\text { WIB }\end{array}$ & Snack time \\
\hline 16 & $\begin{array}{l}15.10-16.00 \\
\text { WIB }\end{array}$ & Review the lesson \\
\hline 17 & $\begin{array}{l}16.00-16.10 \\
\text { WIB }\end{array}$ & Pray Ashar \\
\hline 18 & $\begin{array}{l}16.10-16.30 \\
\text { WIB }\end{array}$ & Playing \\
\hline 19 & $16.30 \mathrm{WIB}$ & Home \\
\hline & $\begin{array}{l}\text { Talents day } \\
\text { eda setiap harinya } \\
\text { nengasah keteramp } \\
\text { ain disebut juga der } \\
\text { enin, talents day } \\
\text { nglish, guru meng } \\
\text { erbahasa inggris. } \\
\text { ang dilakukan }\end{array}$ & $\begin{array}{l}\text { ang dilakukan berbeda- } \\
\text { Hal ini berguna untuk } \\
\text { in anak, dengan bahasa } \\
\text { an ekstrakurikuler. Hari } \\
\text { yang dilakukan yaitu } \\
\text { arkan anak untuk bisa } \\
\text { ari selasa, talents day } \\
\text { itu komputer. Anak }\end{array}$ \\
\hline
\end{tabular}


mengerjakan tugas dalam bentuk game yang ada di komputer, hal ini dilakukan secara bergantian atau bergiliran. Hari rabu, talents day yang dilakukan yaitu mewarnai. Guru mengajarkan anak bagaimana cara untuk menggradasi warna pada gambar dan menggunakan teknik berbeda setiap kegiatannya. Hari kamis, talents day yang dilakukan yaitu menari. Pada semester satu, guru mengajarkan anak menari bebas dan mengikuti irama serta gerakan yang sudah ada. Namun pada semester dua, guru mengajarkan anak menari untuk acara perpisahan di akhir tahun ajaran, seperti Tari Pasambahan, dan tari daerah lainnya. Untuk hari jumat, tidak adanya talents day akan tetapi anak melakukan serangkaian kegiatan islami seperti senandung Al-qur'an dan sholat dhuha berjamaah. Guru juga mengajarkan anak cara berwudhu yang benar, tata cara sholat dan gerakannya, dan membaca hafalan sholat, serta berdzikir.

Setelah proses belajar mengajar di kelas masing-masing selesai, selanjutnya ialah melanjutkan program full day. pukul 12.00 WIB, anak masuk ke ruangan full day untuk mengganti baju sekolah ke baju bebas. Setelah itu anak makan siang bersama-sama dengan nasi dan lauk pauk yang berbeda tiap harinya. Makan siang disediakan oleh pihak sekolah. Kemudian anak mengantri untuk mengambil wudhu dan melakukan sholat dzuhur berjamaah. Setelah sholat dzuhur, anak buang air kecil dan minum susu bagi yang membawa susu. Buang air kecil sebelum tidur diajarkan agar anak tidak mengompol sewaktu tidur siang. Anak berbaring di kasur masing-masing, dan membaca doa sebelum tidur bersama-sama. Guru full day membacakan dongeng hingga anak tertidur. Pukul 15.00 WIB anak dibangunkan dan anak lalu mencuci wajahnya. Anak diarahkan untuk duduk melingkar dan guru menghidangkan buah untuk dimakan anak. Buah yang disediakan juga berbeda tiap hari, ada semangka, pepaya, pisang, jeruk, dan juga ada jelly.
Setelah snack time, anak mengulang pembelajarannya kembali. Guru melakukan tanya jawab dengan anak dan guru juga memberikan tugas sebelum adzan ashar berkumandang. Selanjutnya sholat ashar berjamaah, kemudian anak diperbolehkan bermain bebas dengan teman-temannya sebelum dijemput oleh orang tua. Batas penjemputan anak sebelum jam 16.30 WIB.

Kegiatan ini dilakukan dengan metode pembiasaan. Awalnya, guru memberikan contoh dalam melakukan setiap kegiatan yang telah direncanakan dan membantu anak apabila ada anak yang tidak bisa melakukan tugasnya. Hal ini dilakukan pada semester satu. Namun pada semester dua, guru hanya melihat dan memperhatikan anak dalam melakukan tugasnya. Anak tampak sudah disiplin dan mandiri, tanpa perlu bimbingan dari guru ataupun orang dewasa.

Kendala yang dihadapi dalam penerapan activity schedule ini terdapat pada orang tua dan anak. Anak yang libur sekolah berhari-hari karena harus ikut orang tuanya ke luar kota, maka jadwal yang telah ditetapkan seperti kegiatan sholat dzuhur atau tidur siang tidak dilaksanakan sebagaimana mestinya. Ketika kembali ke sekolah, setelah dua hari dibiasakan kembali maka anak dapat melaksanakan kegiatan yang telah dijadwalkan teraebut.

Evaluasi yang dilakukan guru ialah melalui pengamatan yang mana nantinya dibuat dalam bentuk laporan berupa rapor. Rapor ini diserahkan kepada orang tua selama satu kali dalam tiga bulan. Orang tua dapat melihat perkembangan, dan karakter anak melalui pengamatan yang dilakukan guru full day. Evaluasi program full day school dimaksudkan untuk mengumpulkan informasi mengenai bekerjanya atau tidak program yang telah disusun oleh pihak sekolah.

\section{Pembahasan}

Pendidikan Anak Usia Dini di era sekarang sudah ada beberapa lembaga yang 
menanamkan system sekolah sehari penuh. Eliza (2013) menyatakan untuk terlahirnya generasi-generasi terbaik yaitu dengan melalui pendidikan. Artinya melalui pendidikan ini merupakan cara yang digunakan untuk membentuk kepribadian yang bermoral. Pendidikan anak usia dini diperuntukan untuk anak usia prasekolah yang berguna untuk membentuk karakter anak. Sebagaimana Marlina (2014:110) mengemukakan bahwa anak adalah individu yang sedang mengalami suatu proses perkembangan yang sangat pesat dan sangat fundamental bagi kehidupan selanjutnya. Anak memiliki dunia dan karakter sendiri yang jauh berbeda dengan orang dewasa, mereka sangat aktif, dinamis, antusias, dan hampir dari semua mereka memiliki rasa ingin tahu yang besar terhadap apa yang dia lihat at mereka dengar dan seolah-olah tidak pernah berhenti belajar

Full day school merupakan sekolah yang dilakukan sehari penuh mulai dari pagi hingga sore hari. Taman Kanak-kanak Kreatif Primagama Padang menggunakan program full day school dari pukul 08.0016.30 WIB. Sebagaimana Muzakki (2015:41) menyatakan full day school merupakan layanan pendidikan selama satu hari penuh karena ditinggal oleh kedua orang tuanya yang bekerja. Pada perencanaan pembelajaran di Taman Kanak-kanak Kreatif Primagama Padang guru berpedoman kepada Rancangan Pelaksanaan Pembelajaran Harian (RPPH) yang disusun setiap hari. Pada kegiatan selanjutnya yaitu kegiatan full day school, guru juga merancang perencanaan selama sekali setahun setiap tahun ajaran baru. Sebagaimana Latif (2014:86) mengemukakan bahwa rencana pembelajaran merupakan sebuah panduan dan bimbingan kerja guru yang disusun secara terencana sebagai acuan dalam bekerja, sehingga materi-materi teralirkan dengan metode yang diorganisasikan ke dalam bentuk serangkaian kegiatan serta prosedur kerja.

Pada program full day school menekankan pada kegiatan atau aktivitas sehari-hari yang dialami anak. Sebagaimana karakteristik full day school menurut Siregar (2017:317) merupakan proses integrated activity dan integrated curriculum yang mana dalam pelaksanannya menggunakan metode pengajaran yang menarik minat anak. Activity schedule perlu direncanakan pada program full day school dikarenakan banyak sekali manfaatnya untuk anak. Sesuai dengan pendapat Sunarti (dalam Utami, 2012:239) bahwa pembuatan jadwal aktivitas atau rutinitas harian perlu ditetapkan aturannya. Orang tua perlu menetapkan aturan yang diikuti oleh anak dan kegiatan yang dilaksanakan seperti makan siang, tidur siang, sholat berjamaah, dan lain sebagainya. Sebagaimana Seefeldt (2008:115), di dalam tabelnya ia merancang activity schedule sehari penuh dengan kegiatan seperti persiapan makan siang dengan keterangan anak-anak dipersiapkan untuk makan siang dengan mencuci tangan terlebih dahulu.

Rangkaian activity schedule dibuat oleh guru di Taman Kanak-kanak Kreatif Primagama Padang dan ditempel di dinding kamar tidur anak. Hal ini sama dengan pernyataan yang dikemukakan oleh Kranz (dalam Stromer 2006:14) bahwa format activity schedule dapat berupa buku catatan dengan menggunakan gambar, simbil, dan teks. Activity schedule memiliki tujuan untuk membantu anak dalam mengembangkan kemampuan secara disiplin dan mandiri serta menyelesaikan kegiatan yang telah disusun karena anak belum memiliki manajemen yang baik dalam hidup mereka.

Salah satu manfaat activity schedule ini ialah disiplin. Roslyn (dalam Seefeldt, 2008:181) menyatakan bahwa jadwal seharihari dan rutinitas berlaku sebagai bimbingan dalam mencapai sikap disiplin. Disiplin sangat penting dan dibutuhkan oleh setiap anak karena menjadi prasyarat dalam pembentukan karakter dan tata tertib bagi anak. Siswanto dan Lestari (dalam Noffia, 2015:113) mengemukakan manfaat menanamkan disiplin yaitu mampu memberikan rasa aman kepada anak, 
Jurnal PG-PAUD Trunojoyo : Jurnal Pendidikan dan Pembelajaran Anak Usia Dini, Volume 6,

memberi rasa percaya diri, dan menjadikan anak mandiri.

Activity schedule dalam program full day school perlu dievaluasi dengan maksud untuk melihat apakah terlaksana dengan baik dan mencapai tujuan yang hendak dicapai. Guru mengevaluasi penerapan activity schedule pada anak dengan cara melakukan pengamatan atau observasi. Guru mengamati setiap gerak-gerik, sikap, dan proses kegiatan yang dilakukan anak apakah sesuai dengan target pencapaian dan rancangan jadwal yang telah disusun oleh guru. Evaluasi yang dilakukan sebagian besar sesuai dengan yang direncanakan. Sebagaimana Latif (2014:169) yang menyatakan bahwa evaluasi dikumpulkan dari hasil kerja anak dan dari catatan pengamatan guru. Sesuai dengan pendapat di atas, evaluasi menurut Mahyuddin (2008:7) ialah proses sistematis dalam menentukan nilai sesuatu dengan berdasarkan kriteria tertentu melalui suatu penilaian.

\section{SIMPULAN}

Berdasakan hasil penelitian yang telah peneliti lakukan tentang penerapan activity schedule of full day school dalam menanamkan kedisiplinan di Taman Kanak-kanak Kreatif Primagama Padang dapat disimpulkan bahwa kegiatan yang dilakukan dalam bentuk rutinitas hidup sehari-hari anak yang mana dirancang dengan tersusun dan dilakukan dalam teratur hingga terlaksana dengan baik. Hal ini terlihat dari penerapan activity schedule yang mempengaruhi sikap disiplin pada anak hingga anak mandiri. Anak melakukan kegiatan terjadwal secara rutin dengan metode pembiasaan seperti makan siang, tidur siang, sholat berjamaah, snack time, dan toileting dengan waktu yang telah dirancang. Kemampuan anak melakukan beragam kegiatan tersebut tidak terlepas dari peran guru yang telah merancang kegiatan serta evaluasi yang digunakan. Perencanaan activity schedule dirancang selama sekali setahun setiap tahun ajaran baru. Pelaksanannya sesuai dengan rancangan kegiatan yang telah dibuat oleh guru full day dan penerapannya dilakukan dengan menggunakan metode pembiasaan. Adapun evaluasi yang dilakukan dengan cara observari, yaitu dengan melihat proses kegiatan yang dilakukan anak dalam mengerjakan tugas yang diberikan dan digambarkan dalam rapor.

\section{DAFTAR PUSTAKA}

Arikunto, S. (2016). Manajemen Penelitian. Jakarta: Rineka Cipta.

Budźinska, A., dkk. (2014). Use of Scripts and Script-Fading Procedures and Activity Schedules to Develop Spontaneous Social Interaction In a Three-Year-Old Girl with Autism. Health Psychology Report Volume 2(1)

Eliza, D. (2013). Penerapan Model Pembelajaran Konstektual Learning (CTL) Berbasis Centra di Taman Kanak-Kanak. Pendagogi Jurnal Ilmiah Ilmu Pendidikan. Volume XIII Nomor 2 November 2013

Latif, M., dkk. (2014). Orientasi Baru Pendidikan Anak Usia Dini: Teori dan Aplikasi. Jakarta: Kencana.

Mahyuddin, Nenny. (2008). Asesmen Anak Usia Dini. Padang: UNP Press.

Marlina, S. (2014). Peningkatan Sikap Sosial Anak Usia Dini Melalui Permainan Puzzle Buah di Taman Kanak-kanak Aisyiyah Bukittinggi. PEDAGOGI Jurnal Ilmiah Ilmu Pendidikan Volume XIV Nomor 2 November 2014

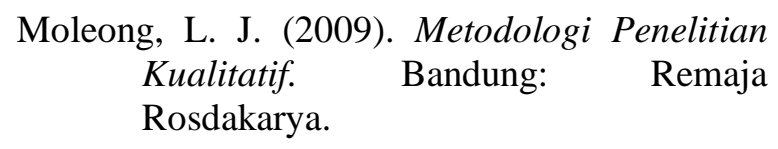

Muzakki. (2015). Implementasi Pembelajaran Anak Usia Dini Berbasis Budaya Lokal di PAUD Full Day School. Jurnal Pendidikan dan Pemberdayaan Masyarakat Volume 2 Nomor 1, Maret 2015 (39-54) 
62 Jurnal PG-PAUD Trunojoyo : Jurnal Pendidikan dan Pembelajaran Anak Usia Dini,

Volume 6, Nomor 1, April 2019, hal 56 - 62

Noffia, I. dan Margaretha. (2015). Mengembangkan Disiplin Anak Usia Dini Melalui Permainan Tradisional. Jurnal Cakrawala Dini: Volume 5 Nomor 2, November 2015

Seefeldt, C. (2008). Pendidikan Anak Usia Dini Menyiapkan Anak Usia Tiga, Empat,dan Lima Tahun Masuk Sekolah. Jawa Tengah: PT.Macanan Jaya Cemerlang.

Siregar, L. Y. (2017). Full Day School Sebagai Penguatan Pendidikan Karakter (Perspektif Psikologi Pendidikan Islam). Jurnal Pendidikan dan Manajemen Islam Volume 05 Nomor 02, Juli 2017

Stromer, R. (2006). Activity Schedules, Computer Technology, and Teaching Children with Autism Spectrum Disorders. Journal Focus On Autism and Other Developmental Disabilities Volume 21 Number 1, Spring 2006

Sugiyono. (2017). Metode Penelitian Pendidikan Pendekatan Kuantitatif, Kualitatif, dan $R \& D$. Bandung: Alfabeta.

Utami, T. (2012). Pengalaman Ibu Mengasuh Anak dengan Resiko GPPH. Jurnal Nursing Studies Volume 1 Nomor 1 Halaman 237-243 